\section{Un ataúd de hierro surcando la ciudad: estética de la soledad posmoderna en Taxi Driver}

This Iron Coffin Floating Through the City: Aesthetics of the Postmodern Loneliness in Taxi Driver

José Luis Valhondo-Crego

¡lvalcre@unex.es

https://orcid.org/0000-0003-2383-5513

Universidad de Extremadura, España.

FECHA DE RECEPCIÓN febrero 4, 2020

FECHA dE APROBACIÓN abril 21, 2020

FECHA DE PUBLICACIÓN julio 1, 2020

https://doi.org/10.32870/ elojoquepiensa.v0i21.351
Resumen / Desde décadas recientes, vivir solo ha dejado de ser algo estadísticamente marginal o socialmente extraño. Por una parte, se ha convertido en una oportunidad vital para alcanzar objetivos personales; por la otra, en un problema social que implica a un número cada vez mayor de individuos. A través de un análisis de contenido, este artículo examina cómo se hace sensible al espectador la soledad a través del caso de estudio del filme Taxi Driver, con guion de Paul Schrader y dirección de Martin Scorsese. Se examina el modo en que se encarna esa soledad en una narrativa cuyo protagonista es un alter ego posmoderno del guionista. Este perpetra con su guion una metáfora del trabajo creativo del artista enfatizando el empleo del diario como una tecnología del yo que pretende ordenar el caos de las imágenes posmodernas. Se deduce que tanto el guionista como el director inscriben la soledad en un relato que apunta a un ciclo necesario de redención y trascendencia.

PALABRAS CLAVE / soledad, alter ego, anonimato, diario, posmodernidad.
Abstract / Since recent decades, living alone has ceased to be something statistically marginal or socially strange. On the one hand, it has become a vital opportunity to achieve personal goals; on the other, in a social problem that involves an increasing number of individuals. This article examines how loneliness becomes sensitive to the viewer through the case study of Taxi Driver, with a script by Paul Schrader and directed by Martin Scorsese. The way in which this solitude is embodied is analyzed in a narrative whose protagonist is a postmodern alter ego of the screenwriter. He writes with his script a metaphor of the artist's creative work emphasizing the use of the diary as a technology of the self that aims to order the chaos of postmodern images. It follows that both the screenwriter and the director inscribe loneliness in a story that points to a necessary cycle of redemption and transcendence.

KEYWORDs / loneliness, alter ego, anonymity, diary, postmodernism. 

o una comunidad. Hasta la segunda mitad del siglo xx XX, vivir solo era una excentricidad, de manera que la sociedad se había organizado en torno al núcleo familiar.

En primer lugar, se tratará la cuestión del alcance y metodología seguida para el análisis. En una segunda parte, exponemos los resultados del proceso por el que Paul Schrader "se traduce" o realiza un ejercicio de interpretación de sus imágenes personales para transformarlas en un guion y cómo Martin Scorsese vuelve a transformar esa escritura en imágenes. Exploramos el modo en que se conectan sociedad y sujeto posmoderno en Taxi Driver. Finalmente se ofrecen conclusiones sobre la interacción de imágenes y palabras en la construcción cinematográfica de la soledad como problema social.

\section{Alcance Y METODOLOGÍA EMPLEDA}

Se analizará el modo estético en que el guion de Taxi Driver se ha convertido en un texto audiovisual. Con "modo estético" nos referimos al significado primigenio de la estética como experiencia de los sentidos; dicho de otra manera, cómo se genera un discurso para que el espectador interprete emocionalmente la soledad de un individuo en un contexto posmoderno caracterizado por la disolución de las identidades, la incomunicación, la anomia y la alienación.

Las unidades de análisis en el guion serán las intervenciones de los personajes y las acotaciones; en el caso del filme, los planos y las escenas constituirán las unidades a examinar. El objetivo es comparar el texto del guion con el resultado final de la edición del filme, centrándonos en la caracterización del protagonista. El guion de Paul Schrader (1976) puede consultarse en internet. Las imágenes del filme han sido analizadas a partir de una edición en DVD de 1999. Para facilitar el análisis cualitativo se ha empleado una herramienta informática [ANEXO 1].

Debemos hacer una precisión respecto al alcance del estudio. Se examina solo un fragmento de la película que consideramos clave para explorar la estética respecto a la soledad posmoderna. En concreto, ese fragmento abarca desde el comienzo del filme hasta el primer punto de giro, que consideramos el momento en que Travis descubre a Betsy. Tenemos en cuenta el resto del filme como contexto narrativo, pero la comparación detallada entre el guion y su producción abarca hasta ese punto.

También es necesario señalar que contextualizaremos el análisis en el marco del proceso creativo entre el guionista (Paul Schrader) y el director (Martin Scorsese). Schrader encontró en Scorsese a alguien afín a sus presupuestos estéticos. Scorsese también creció en una subcultura muy religiosa, la de la comunidad italoamericana de posguerra en Nueva York. Pensó de joven en ordenarse sacerdote, para terminar abrazando el cine como profesión, con una fe casi religiosa en las imágenes. En ese marco, el guionista trabaja en muchas ocasiones traduciendo sus propias imágenes mentales sobre el tema al texto del guion, tal y como ocurre con el caso mencionado del taxi apareciendo en mitad de la bruma neoyorkina. Este proceso es inverso al que realiza el director cuando traduce ese guion a imágenes para editarlas en el último tramo del trabajo. Por resumir, el proceso incluye la transición creativa desde las imágenes en la mente del guionista hasta las del director, con la conexión intermedia del guion.

\section{ESTETIZAR LA SOLEDAD A TRAVÉS DEL PROTAGONISTA}

Scorsese abre su película con la aparición fantasmagórica de un Chevrolet amarillo que surge entre la bruma, flotando entre el vapor que emanan las calles de Nueva York [FIGURA 1]. Traduce así la metáfora de Schrader cuando este imaginó el germen de su guion como "un ataúd de hierro surcando la ciudad" (aunque dicha expresión no figurara en el guion).

Un guion clásico no suele abrir con una cita, pero Schrader lo hace con una frase del escritor Thomas Wolfe: "La mayor convicción de mi vida reside ahora en la creencia de que la 
FIGURA 1. Taxi emergiendo en la bruma (Taxi Driver, dirigida por Martin Scorsese con guion de Paul Schrader, 1976).

FIGURA 2. "Detrás de esa sonrisa, tras sus oscuros ojos" (Taxi Driver, dirigida por Martin Scorsese con guion de Paul Schrader, 1976).
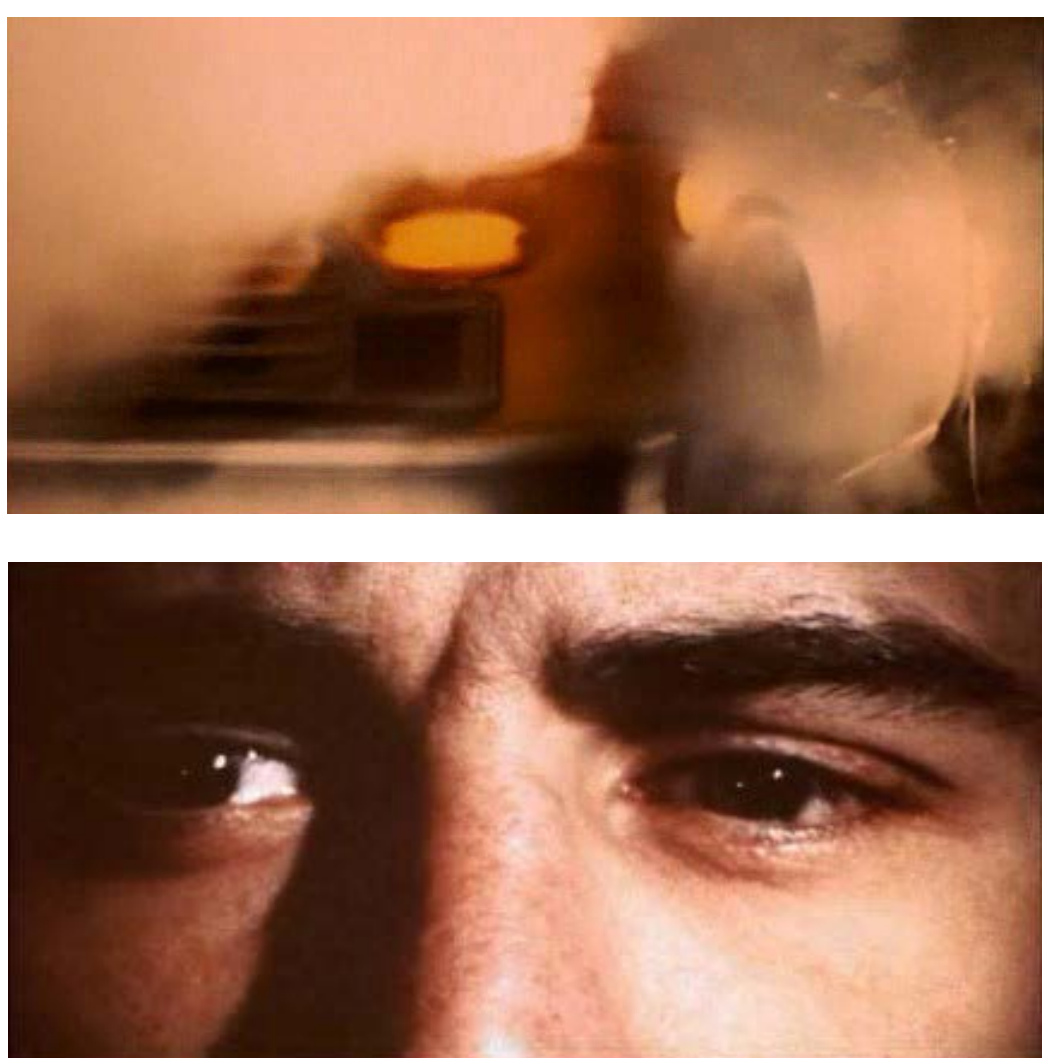

soledad, lejos de ser un raro y curioso fenómeno, es el hecho fundamental e inevitable de la existencia humana" (God's Lonely Man, 1941). Emplear esa cita forma parte del pastiche posmoderno de la película y funciona a modo de tono o clave de la melodía de lo que vendrá después en el resto de la pieza. Esa clave gira en torno a la conciencia humana de la soledad tal y como el propio Schrader reconoce (citado en Brady, 2013); una soledad que el personaje rumia a lo largo de toda la película.

\section{RASGOS OBJETIVOS Y ESTADOS MENTALES}

Tras esa cita inicial que enmarca y pretende dar sentido a la trama, el guion destaca la descripción del protagonista. En este tipo de descripción encontramos elementos objetivos para un posible observador: "TRAVIS BICKLE, 26 años, delgado, curtido, el perfecto solitario (...) Viste tejanos y botas de vaquero, una camisa de cuadros y una raída cazadora del ejército con un lema donde se puede leer 'King Kong Company 1968-1970"' (Schrader, 1976, p. 2)'.

Frente a esas descripciones objetivas localizamos en esa acotación la descripción de estados mentales que solo pueden ser leídos a través de la observación de la conducta externa. Por ejemplo, cuando el guion señala lo siguiente: "Detrás de esa sonrisa, tras sus oscuros ojos, en sus mejillas demacradas, podemos ver las manchas ominosas causadas por una vida de miedo íntimo, de vacío, de soledad" (p. 2)². Subrayamos el "podemos ver" porque es el elemento clave que explica ese estilo clásico: ¿quién puede ver qué?

\footnotetext{
16'TRAVIS BICKLE, age 26, lean, hard, the consummate loner (...) He wears rider jeans, cowboy boots, a plaid western shirt and a worn beige Army jacket with a patch reading, 'King Kong Company 1968-70'” (La traducción es mía).

"But behind that smile, around his dark eyes, in his gaunt cheeks, one can see the ominous stains caused by a life of private fear, emptiness and loneliness" (La traducción es mía).
} 
El guionista hace un esfuerzo interpretativo e intenta traducir el sentido de esos gestos del personaje, que en apariencia son risueños, pero tras los cuales se esconde algo muy diferente. Infiere en la cara de su posible alter ego esos sentimientos e intenta comunicarlos al espectador. Por su parte, el director traduce esa descripción en una serie de planos de la mirada de Travis a su espejo retrovisor [FIGURA 2] que, además, forman parte de los créditos de la presentación de la película y están editados justo después de la aparición del taxi en la niebla.

Se puede deducir que Schrader caracteriza a su personaje a través de la capacidad de entender los sentimientos ajenos gracias a la imitación interna y mental de esos gestos. El guionista brinda al actor y al director señales para construir los gestos de Travis que él "ve" en su mente, para que el espectador pueda representarse a Travis al "reconocer" con la mirada interior esos gestos.

Schrader despliega también en esa descripción inicial un registro aún más subjetivo respecto a su personaje, relacionado con una imagen ambigua. Lo hace cuando apunta que "parece haber deambulado por un mundo frío, un lugar donde la gente apenas se comunica". Se trata de una descripción posibilista y metafórica, en que el autor propone un boceto difuso, nada clásico, del personaje; como si hubiera algo en él que se escapa al autor y que quiere compartir con el espectador. Lo clásico sería recurrir a la capacidad omnisciente del autor, pero opta por lo posmoderno, en el sentido de que con estas descripciones revela su imposibilidad de concretar al personaje, hacerlo cognoscible. De hecho, el autor parece no creer en la posibilidad de cerrar el conocimiento sobre Travis.

\section{EL INDIVIDUO FRENTE A LA MASA}

Otro elemento en esa descripción inicial del personaje lo relaciona con el resto de la sociedad. "Travis va a la deriva en la vida nocturna de Nueva York, como una oscura som- bra entre otras sombras aún más oscuras. Pasando desapercibido, sin motivos para que nadie se fije en él. Travis parece camuflarse entre lo que le rodea" (p. 2) ${ }^{3}$. En la traducción de esas palabras a imágenes, Scorsese opta por unas imágenes de las calles de Nueva York [FigurA 3], y las sitúa justo después de mostrar la mirada de Travis [Figura 2]. Son imágenes distorsionadas de gente anónima, con filtros de colores primarios (rojo y azul) que dejan estelas, en cámara ralentizada. Figuras fantasmagóricas u oníricas se pasean delante de la mirada del taxista y le devuelven esa mirada. Se trata de la masa indistinguible de Nueva York. La ciudad funciona como otro personaje del relato.

Las imágenes de los créditos proponen unas coordenadas estéticas y temáticas condensadas y traducidas en tres símbolos básicos que se encadenan en la secuencia: Taxi, Mirada de Travis, Muchedumbre. Hablamos de una sintaxis visual que se replica a lo largo del guion para incidir en la subjetividad del relato a través de los ojos de Travis, además de señalar la separación entre el taxista y la realidad indescifrable que cada noche observa. La música de Bernard Herrmann refuerza el tono de esa imagen de entrada, un tono onírico mezclado con momentos que retornan siempre a la inquietud.

La descripción de Travis y la metáfora (no presente en el guion) del taxi surcando la ciudad han servido para generar un flujo de imágenes que provoca una pregunta: ¿quién está mirando y quiénes son los que devuelven la mirada? En parte, de forma clásica, la siguiente escena responde esa pregunta: el protagonista, Travis Bickle, no puede dormir por las noches y acude a una empresa de taxis para hacer algo de provecho con su insomnio. Comienza a merodear por la ciudad trabajando como taxista.

\footnotetext{
3"Travis is now drifting in and out of the New York City night life, a dark shadow among darker shadows. Not noticed, no reason to be noticed" (La traducción es mía).
} 


\section{UN DIARIO PARA RACIONALIZAR LAS IMÁGENES}

Aparte de los tres elementos simbólicos mencionados: Taxi, Mirada y Muchedumbre (o Nueva York), aún falta un cuarto elemento para terminar de articular el discurso visual: el diario que escribe Travis y su traslación a la pantalla en forma de voice over ${ }^{4}$. Para poder cerrar el significado abierto de las imágenes de entrada (y del resto de la trama), el guionista recurre a un diario. Scorsese toma del guion el primer monólogo en voice over (V. O. en adelante) y lo edita con imágenes de una panorámica del interior de la vivienda de Travis hasta llegar al protagonista, que primero está escribiendo un diario y después conduce el taxi.

En el guion encontramos lo siguiente: "La CÁMARA realiza una panorámica, examinando el apartamento de Travis.

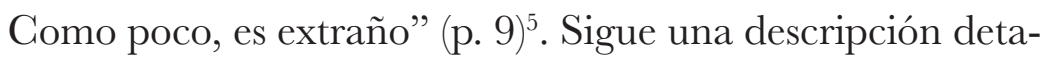
llada del apartamento que Scorsese reflejará en sus detalles. La vivienda se convierte también en otro elemento de la personalidad que refleja la soledad de Travis. Es una vivienda de alguien que no la comparte con nadie, ni siquiera para invitarlo a pasar un rato. "No hay mobiliario, más allá de una silla minúscula (...) unos cables rotos cuelgan en la pared donde en otro tiempo hubo un teléfono" (p. 9) .

La continuidad se asegura gracias a esa voz interna de Travis cuya significación estética principal en el filme consiste en intentar fundir relato e identidad del personaje. En el fondo, ese diario se parece a lo que Roland Barthes (1977) señalaba en su ensayo sobre retórica de la imagen respecto

\footnotetext{
${ }^{4}$ Empleamos el término original, voice over, para distinguirlo de la voz en off. La voice over es una voz extradiegética, que no escucharíamos como testigos si estuviéramos en la escena, cosa que sí ocurriría con la voz en off, que es diegética pero fuera de cuadro.

5“'CAMERA continues to PAN, examining TRAVIS' apartment. It is unusual, to say the least" (La traducción es mía).

${ }^{6 "}$ "There is no furniture other than the rickety chair and table (...) Ragged black wires dangle from the wall where the telephone once hung" (La traducción es mía).
}

al anclaje que ejercen los pies de foto en las imágenes que comentan.

El flujo de conciencia no es un recurso clásico en la construcción del personaje fílmico. Se trata de una estrategia del guionista que comunica a su personaje mientras este cuenta el relato de su identidad. Es posible que ese flujo conectara con el solitario estado emocional de Schrader y que este lo transfiriera al guion a través de la utilización narrativa del diario. Estéticamente, también comunica algo muy importante: Travis no escribe un diario por placer expresivo, lo hacer como ejercicio de control.

Michel Foucualt (1990) consigna el diario entre esas herramientas o tecnologías del yo con las que el sujeto moderno intenta someterse a su propia disciplina. Travis está obsesionado con la organización de sus cosas domésticas, lo que viene a reflejar también su necesidad de un orden social autoritario. Especulando con el trabajo artístico de Schrader, es posible que el diario sirviera tanto al guionista como al personaje. El primero recurre a esta técnica para orientar el curso del relato, del mismo modo que el personaje la emplea para ordenar su existencia. Nos basamos en que Schrader ha continuado utilizando este recurso en filmes que ha escrito y dirigido (Light Sleeper, 1992; First Reformed, 2017).

Las intervenciones de Travis en su diario jalonan el arco de transformación del personaje que inventa objetivos con el fin de estructurar su caótica existencia. A diferencia de un relato tradicional, y con ello de un sujeto clásico, este personaje tiene como objetivo encontrar un objetivo. Desde el punto clásico del guion restaurativo (Dancyger y Rush, 2013), el personaje tiene un objetivo y enfrenta unas resistencias, buscando restaurar su equilibrio. Travis Bickle no es un sujeto clásico ni la trama de su existencia se cuenta como un guion restaurativo.

Con el V. O., Schrader muestra en su texto algo que los guionistas suelen dejar como parte del andamiaje de su obra. $\mathrm{Al}$ mostrar ese andamiaje incurre también en la práctica posmoderna de revelar el artificio, de transgredir la idea clásica de narración según la cual el relato debe borrar las huellas 

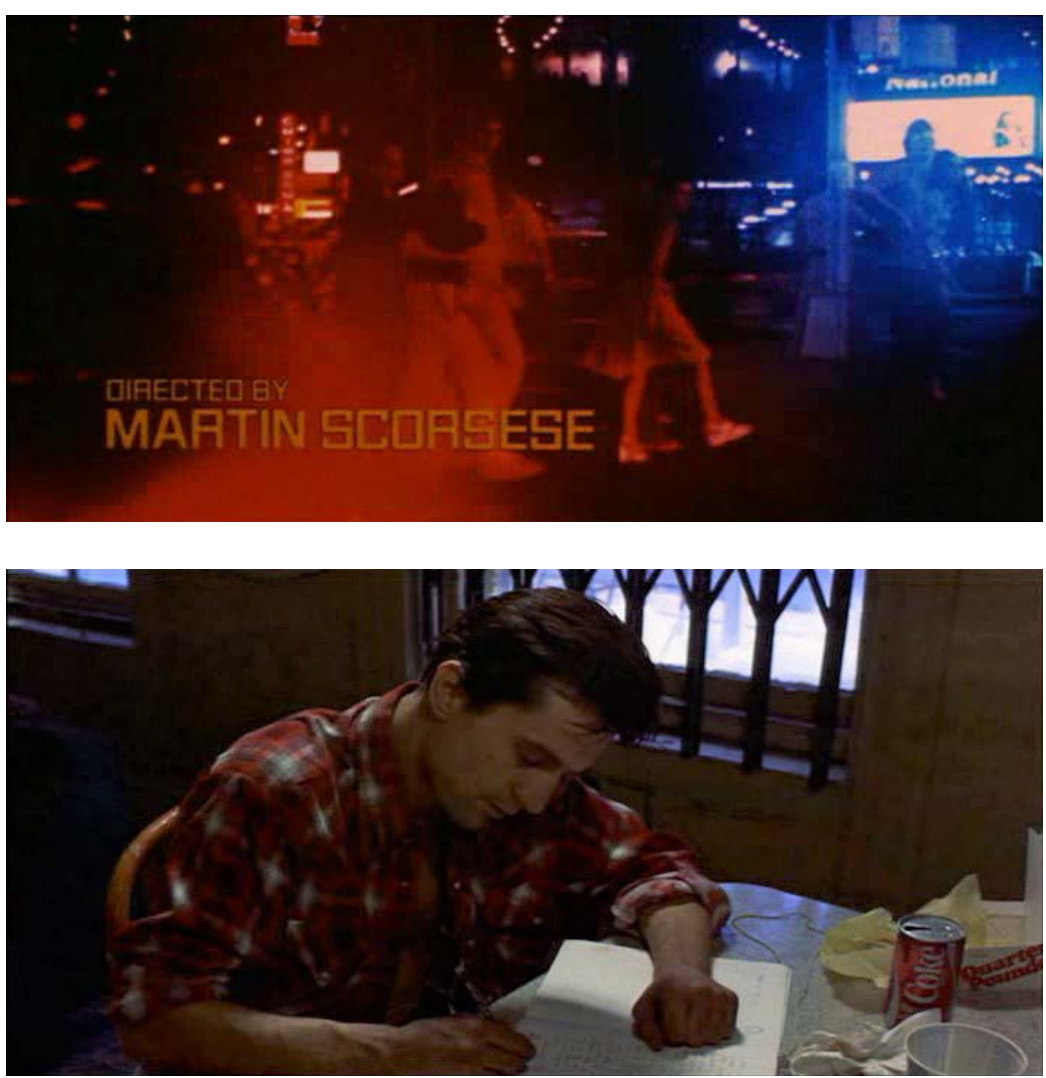

de quien lo enuncia. Ese andamiaje coincide con un ejercicio que los teóricos del guion recomiendan realizar para construir al personaje como subtexto, aunque nada de ello aparezca después en el guion (McKee, 2009). A Schrader le sirve como herramienta para hacer sensible la naturaleza de su personaje y renovar el recurso del v.o. del noir clásico, con un sentido aún más existencialista [FIGURA 4].

Hemos señalado que el v.o. puede servir al guionista para construir los recodos del curso de su trama. Tanto es así que el punto medio de la película o punto de crisis, según la teoría del guion, está dominado por una intervención en el diario, con función expresiva y estructural: "La soledad me ha perseguido durante toda mi vida, por todas partes: en los bares, en los coches, en las aceras, en las tiendas, por todas partes, no tengo escapatoria, soy un hombre solitario" (Schrader, 1976, p. 98)7. "Expresiva" porque figura como elemento clave

\footnotetext{
${ }^{76}$ Loneliness has followed me all my life. The life of loneliness pursues me wherever I go: in bars, cars, coffee shops, theaters, stores, sidewalks. There is no escape. I am God's lonely man" (La traducción es mía).
}

FIGURA 3. "Una oscura sombra entre sombras aún más oscuras"

(Taxi Driver, dirigida por Martin Scorsese

con guion de Paul Schrader, 1976).

FIGURA 4. Travis escribe un diario narrado en voice over.

(Taxi Driver, dirigida por Martin Scorsese

con guion de Paul Schrader, 1976).

para comprender el estado emocional del personaje. Desde la perspectiva aristotélica se trata de la anagnórisis o toma de conciencia del protagonista. "Estructural" porque coincide con el punto crítico en el cual Travis decide pasar a la acción. A partir de este momento en la trama, el v.o. desaparece y deja paso a la acción del protagonista, como en el relato clásico. La intervención parafrasea la cita de Thomas Wolfe con la que Schrader enmarca su guion y se cita de tal modo que suena como elemento central de la existencia de Travis, como una falta original o una fatalidad del destino.

La primera parte del filme exhibe un esfuerzo denodado por parte del protagonista por ordenar su mundo, en especial su percepción. Schrader construye a Travis Bickle señalando cómo percibe la realidad de las calles desde su coche, desde su ataúd de metal con ruedas, y qué significado confiere a lo que ve. Para eso, el guionista muestra qué ve el personaje, su acoplamiento estructural a la realidad (Maturana y Varela, 1990). El personaje destaca una figura sobre un fondo de su mundo 
circundante, al tiempo que produce una interpretación sobre él.

Hemos apuntado que la multitud anónima de Nueva York es un personaje indispensable en esta historia. Travis se siente solo frente a esa masa. Su personaje se encarna frente a esa muchedumbre solitaria a la que teme [FIGURA 5]. Si al inicio del filme se muestra ya esa imagen [FIGURA 3], con la incorporación del v.o., se añade la interpretación que Travis le confiere: "Por la noche salen bichos de todas clases: furcias, macarras, maleantes, maricas, lesbianas, drogadictos, traficantes de drogas" (Schrader, 1976, p. 9) ${ }^{8}$. Repetirá el mismo pensamiento más tarde y el guionista mostrará el mundo a través de los ojos de Travis para que podamos representárnoslo como él lo ve: "Nuestros ojos radiografían las hileras de peatones - desahuciados, yonkis, turistas, putas, homosexuales, hippies- . Todos ellos se confunden en las aceras frente a los escaparates iluminados y no significan nada" (p. 36) ${ }^{9}$. Se trata de una masa informe, sin cara, deshumanizada y anónima frente a la que Travis experimenta miedo y asco.

Schrader sigue la técnica de comunicar al personaje desde dentro-afuera, tal como prescribiría Stanislavski (1975), tanto con su flujo de pensamiento como con su percepción.

\section{Porno COMO REFugio DE LAS MULTITUDES}

Tras terminar su turno, Travis entra en un cine porno. Intenta entablar una conversación con la empleada del stand de bebidas. Esta lo rechaza y amenaza con llamar al jefe. Travis pide algo y se sienta en la sala. Mientras mira la pantalla y suena de fondo la distorsión de lo que parecen unos gemidos de placer, escuchamos de nuevo el v.o.: "Doce horas de trabajo y sigo sin poder dormir. Los días pasan uno

\footnotetext{
${ }^{86}$ They're all animals anyway. All the animals come out at night: Whores, skunk pussies, buggers, queens, fairies, dopers, junkies, sick, venal" (La traducción procede del doblaje español del filme).

9"Our eyes scan the long lines of PEDESTRIANS. The regular — bums, junkies, tourists, hookers, homosexuals, hippies” (La traducción es mía).
}

tras otro, parece que no tienen fin" (Schrader, 1976, p. 13) ${ }^{10}$. Travis frecuenta los cines porno tal y como hacía Schrader en su mala racha, cuando vivía en su coche. Resulta interesante destacar este hábito del personaje en la representación de la soledad porque tiene relación con otra dimensión de su aislamiento: su forma de concebir la sexualidad. En la descripción inicial de Travis, Schrader apunta lo siguiente: "Desprende olor a sexo: sexo enfermizo, reprimido, solitario, pero sexo, al fin y al cabo. Una desbocada energía masculina que le empuja no sabemos en qué dirección" (p. 2) ${ }^{11}$. Su mirada ante el flujo pornográfico de las imágenes refleja la misma impotencia que siente respecto a asimilarse a la masa que le rodea. En esa representación de la soledad, la posición del espectador de porno en el cine replica la del conductor del taxi. Mira sin actuar, sin poder someter sus prejuicios a examen. Las imágenes sustituyen su experiencia con la realidad y lo mantienen a distancia de esta. En ambas situaciones, el taxi y la butaca del cine le sirven como refugio frente a las multitudes.

\section{BETSY: LA MULTITUD SE INDIVIDUALIZA}

Para definir al personaje y su soledad requerimos saber cómo construye su percepción respecto a otros sujetos. Travis lo hace a través de esas opiniones sobre los demás. Asistimos a esa focalización de los personajes en el guion a través de una combinación del punto de vista subjetivo (como POV en el guion, Point of View) o, como ya hemos señalado, con el voice over. A lo largo del texto, Schrader emplea explícitamente POV en cinco ocasiones, aunque sus acotaciones también den pie a que el director focalice el relato desde la

\footnotetext{
10“'Twelve hours of work and I still cannot sleep. The days dwindle on forever and do not end" (La traducción procede del doblaje español del filme).

11، He has the smell of sex about him: Sick sex, repressed sex, lonely sex, but sex nonetheless. He is a raw male force, driving forward; toward what, one cannot tell" (La traducción es mía).
} 
mirada de Travis, empleando para ello expresiones como "uno puede ver" o "Nuestros ojos escanean ahora".

Frente a la masa informe, el relato hace emerger a Betsy. Aquí Scorsese recrea el guion de Schrader con una puesta en escena diferente. En vez de estar sentada en las oficinas (en el guion), Betsy aparece caminando en slow motion mientras entra en esas oficinas. Esta opción estilística aumenta el efecto de fascinación. El propio Scorsese aparece en el plano en el que vemos por primera vez a Betsy [Figura 6]. Justo antes, Scorsese también opta por planos de día para representar a la masa, pero siguiendo la lógica de la distorsión de la mirada de Travis, el director escoge un gran angular con steadycam, produciendo una impresión de extrañeza.

Betsy le sirve al guionista para mostrar al personaje al modo tradicional, a través de los ojos de otro personaje. En el guion, Travis se dirige hacia la oficina a presentarse a Betsy. Tras hacerlo le confiesa que es la mujer más bella que ha conocido. Antes de mostrar la respuesta de Betsy, Schrader describe su pensamiento:

BETSY por un momento queda atónita, aunque encantada. La presencia de TRAVIS tiene esa carga sexual definitiva. Tiene esas cualidades especiales que BETSY busca. Ella siente que hay algo especial en ese joven que está frente a ella. Además, está esa sonrisa que la desarma. Él es, como diría Betsy, 'fascinante' (p. 27) ${ }^{12}$.

Schrader vuelve sobre la descripción de TRAVIS; primero lo comunica de forma objetiva ("La presencia de TRAVIs tiene esa carga sexual definitiva"), pero de inmediato lo conecta con la aspiración de Betsy, de manera que la construcción de Travis adquiere un sentido a través de otro personaje. Se anima al espectador a percibir el deseo sexual en Travis. Schrader ya muestra esto en su descripción inicial de Travis en el guion. Sin embargo, aquí cambia de registro y confirma ese

\footnotetext{
12“'BETSY is momentarily taken back, but pleased. TRAVIS' presence has a definite sexual charge. He has those star qualities BETSY looks for: She senses there is something special about the young man who stands before her. And then, too, there is that disarming smile. He is, as Betsy would say, 'fascinating"” (La traducción es mía).
}

perfil empleando a Betsy como recurso: "Ella siente que hay algo especial en ese joven que está frente a ella". Y a través de lo que incluso diría Betsy si hablara de él: "Él es, como diría Betsy, "fascinante".

Por primera vez en el relato, Travis consigue establecer cierta intimidad con otro ser humano, individualizar a esa masa que teme, dar un paso para encarnar la fantasía del porno en alguien que le atrae sexualmente. Por eso el espectador puede quedar atónito cuando en la primera cita, Travis invita a Betsy a un cine porno. En la línea del sujeto posmoderno, las motivaciones de Travis parecen inescrutables.

Cattrysse (2010) ha redefinido los conceptos de deseo y necesidad en el guion: el deseo se relaciona con el objetivo del personaje en la trama, la necesidad conecta la historia con el público. El deseo de Travis es individualizar a Betsy pero su necesidad le empuja a disolverla en la multitud, representada en la fantasía del porno. De algún modo, cosificar a Betsy protege a Travis de su propio deseo, tal y como la pantalla pornográfica le mantiene a distancia de la experiencia real.

\section{SOLEDADES MODERNAS Y POSMODERNAS}

Taxi Driver brinda al espectador una representación de la soledad posmoderna a través de su encarnación en un sujeto cuya caracterización fundamental procede de la escritura de un diario con el que pretende, a través de la palabra, domesticar su imagen propia y la de los otros. Como recurso disciplinario, el diario no alcanza para crear un relato satisfactorio para el protagonista. A diferencia del relato clásico, este no contempla un objetivo diáfano que oriente la acción. El protagonista vagabundea, no solo de modo literal, también como metáfora de su búsqueda personal de sentido entre la multitud de imágenes. Dicho de otro modo, el objetivo del personaje se centra en descubrir su objetivo en la vorágine de significados que le rodean.

La escritura del guion de Schrader relata, como en un ensayo, la conformación de la identidad de Travis. 
El guionista desnuda ese proceso que la modernidad daba por sentado cuando señalaba que el sujeto es capaz de crear un relato propio coherente y ordenado de sí mismo. La soledad de Travis es la del individuo que lidia por construir un relato de significados sólidos, una soledad que parece necesaria para redimirse. En esa construcción juegan un papel fundamental las imágenes que el protagonista pretende domesticar con la palabra. El taxi lo protege y aísla de las imágenes de la masa que observa en las calles, frente a la que se construye por identificación negativa. Él es todo lo que esa masa no es; aunque, por supuesto, muchas de sus conductas reflejen ese caos del que rechaza formar parte. En vez de someter sus prejuicios sobre esas imágenes a un contraste experiencial, Travis se limita a la posición del voyeur desde el asiento del taxi, la butaca del cine porno o la silla frente a la televisión.

FIGURA 5. "Por la noche salen bichos de todas clases" (Taxi Driver, dirigida por Martin Scorsese con guion de Paul Schrader, 1976).

FIGURA 6. "La vi por primera vez..." Taxi Driver, dirigida por Martin Scorsese con guion de Paul Schrader, 1976).
La soledad es una soledad frente a las imágenes que saturan su mapa de significados sociales.

A diferencia del relato clásico, el espectador no consigue leer en el protagonista unas motivaciones del pasado que logren explicar la conducta de Travis. Su perfil tampoco incluye identificación de clase de ningún tipo (económica, social o política). Como mucho, Travis hace gala de unos valores culturales muy conservadores respecto al entorno en el que vive. En definitiva, creemos que Schrader pretende dejar claro que Travis Bickle es un enigma incluso para él mismo, tal y como queda bien fundamentado en los diálogos del guion que entabla con Betsy o Wizard. Por ello, emprende un ciclo de redención y trascendencia para explorar ese enigma y luchar en la batalla por el sentido de su propio yo.
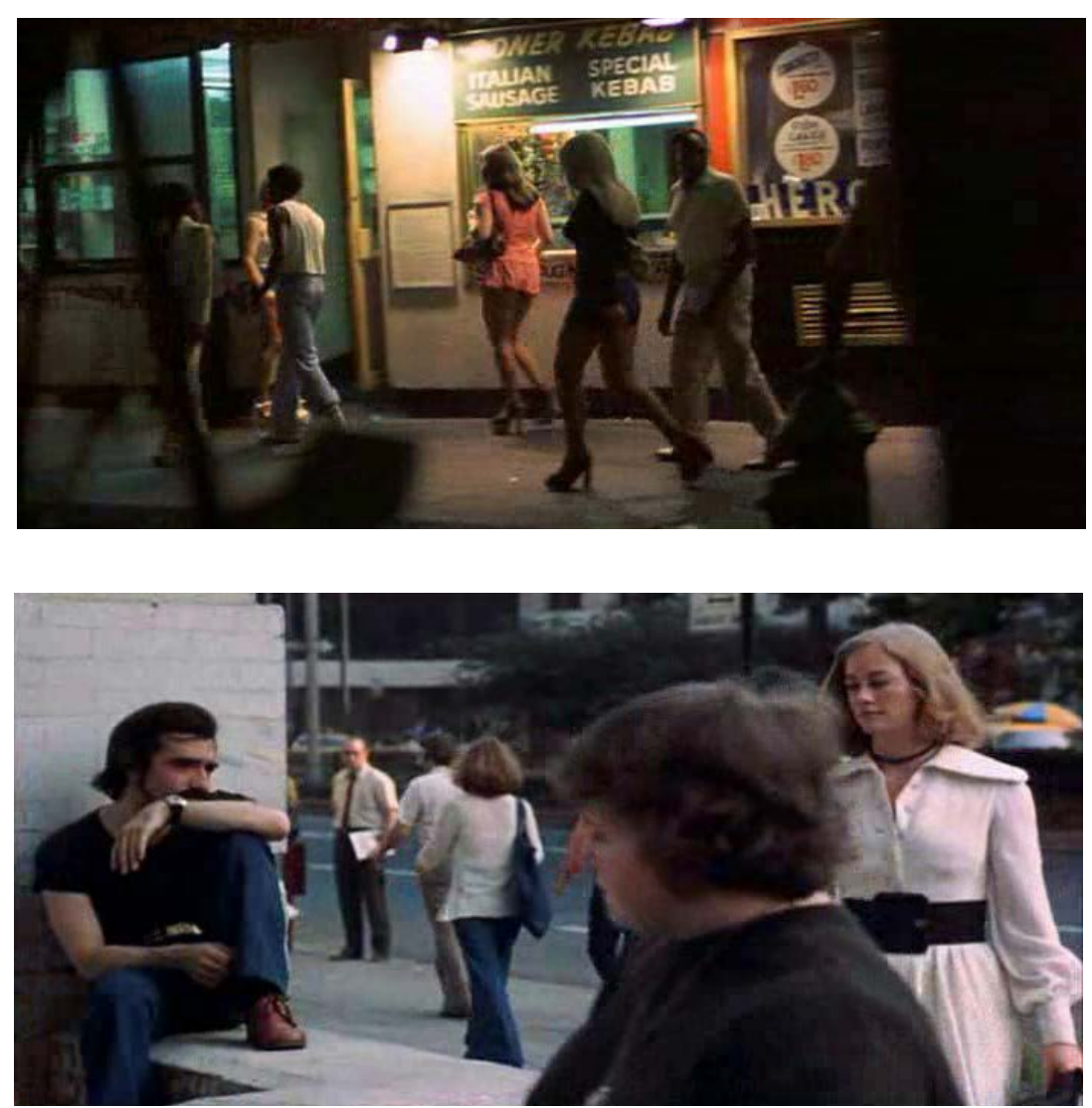
Baker, A. (Ed.). (2015). A Companion to Martin Scorsese. Malden, EE.UU.: Wiley Blackwell. Barthes, R. (1977). Image Music Text. Nueva York, EE.UU.: Hill and Wang.

Benjamin, W. (2017 [1935]). The Work of Art in the Age of Mechanical Reproduction. En D. Goldblatt, L.B. Brown, y S. Patridge (Ed.), Aesthetics: A Reader in Philosophy of the Arts (4a ed.). Londres, Reino Unido: Taylor \& Francis. doi: https: / / doi.org/10.4324/9781315303673

Brady, J. (2013). The Craft of the Screenwriter. Nueva York, EE.UU.: Simon and Schuster.

Cattrysse, P. (2010). The Protagonist's Dramatic Goals, Wants and Needs. Fournal of Screenweriting, 1(1), 83-97. doi: https://doi.org/10.1386/josc.1.1.83/1

Dancyger, K. y Rush, J. (2013). Alternative Scriptweriting. Beyond the Hollywood Formula (5a ed.). Burlington, EE.UU.: Taylor \& Francis.

Foucault, M. (1990). Tecnologías del yo y otros textos afines. Barcelona, España: Paidós.

Genette, G. (1983). Narrative Discourse: An Essay in Method. Ithaca, EE.UU.: Cornell University Press.

Kolker, R. P. (2011). A Cinema of Loneliness: Penn, Stone, Kubrick, Scorsese, Spielberg, Altman (4a ed.). Oxford, Reino Unido: Oxford University Press.

Konow, D. y Mercurio, J. (14 de noviembre de 2015). Transformation in Art: The Films of Paul Schrader. Creative Screenwriting. Recuperado de: https://creativescreenwriting.com/transformation-in-art-the-films-of-paul-schrader/

Klinenberg, E. (2013). Going Solo: The Extraordinary Rise and Surprising Appeal of Living Alone. Nueva York, EE.UU.: Penguin Press.

Maturana, H. y Varela, F. (1990). El árbol del conocimiento: las bases biológicas del conocimiento humano. Madrid, España: Debate.

McKee, R. (1997). Story: Substance, Structure, Style and the Principles of Screenwriting. Nueva York, EE.UU.: Regan Books.

Schrader, P. (1976). Taxi Driver [Guion cinematográfico]. Recuperado de: http:// www.sellingyourscreenplay.com/wp-content/uploads/screenplay/scripts/ Taxi-Driver.pdf

Schrader, P. (2018). Transcendental Style in Film: Ozu, Bresson, Dreyer. Oakland, EE.UU.: University of California Press.

Stanislavski, G. (1975). La construcción del personaje. Barcelona, España: Alianza.

Taubin, A. (2012). Taxi Driver. Londres, Reino Unido: Bloomsbury Academic.

Thompson, R. (1976). Interview: Paul Schrader. Film Comment. Recuperado de: https:/ / www.filmcomment.com/article/paul-schrader-richard-thompson-interview/

Wade, C. (2017). Martin Scorsese's Taxi Driver. Reino Unido: Wisdom Twin Books. 


\section{Filmografía}

Scorsese, M. (Director) \& Philips, J. y Philips, M. (Productores). (1976). Taxi Driver. EE.UU.: Bill/Phillips Productions.

José Luis Valhondo-Crego (España) se licenció en Filosofía y Ciencias de la Educación (Psicología) y en Comunicación Audiovisual en la Universidad de Salamanca (España). También se formó como periodista en la Universidad del País Vasco. Actualmente trabaja como docente e investigador en la Universidad de Extremadura (España). Ha publicado en 2019 un libro sobre estudios fílmicos titulado Econarrativa audiovisual y teoría de la mente. 
ANEXo 1. Código de análisis.

\section{Información sobre filme}

a. Año de producción

b. Equipo creativo

c. Duración

d. División estructural

\section{Caracterización de personajes guion/imágenes}

a. Deseos y necesidades

b. Rasgos objetivos

c. Estados mentales

i. Inferidos por conducta

ii. Ambiguos

d. Voice over

i. Relato identitario

ii. Sobre otros personajes

e. Planos subjetivos (POV)

f. Contraste con otros personajes 